\title{
Research on Green Innovation Efficiency of Listed Chinese Energy Companies Based on Triple Bottom Line
}

\author{
Zhimin Song ${ }^{1}$ and Na Zhang $\mathbb{D}^{2}$ \\ ${ }^{1}$ School of Business Administration, Southwestern University of Finance and Economics, Chengdu 611130, China \\ ${ }^{2}$ School of Economics and Management, Shihezi University, Shihezi 832000, China \\ Correspondence should be addressed to Na Zhang; zhangnanuaa@163.com
}

Received 2 June 2020; Revised 24 July 2020; Accepted 3 August 2020; Published 5 October 2020

Academic Editor: Yan-Ling Wei

Copyright ( ) 2020 Zhimin Song and Na Zhang. This is an open access article distributed under the Creative Commons Attribution License, which permits unrestricted use, distribution, and reproduction in any medium, provided the original work is properly cited.

\begin{abstract}
This paper, based on the panel data, measures the comprehensive efficiency of green innovation, the economic output efficiency of green innovation, the social output efficiency of green innovation, and the environmental output efficiency of green innovation of listed energy companies in China by means of the window DEA model from the perspective of the triple bottom line. Moreover, the impacts of environmental factors and random factors on the green innovation efficiency are analyzed. It is found that firstly, green innovation efficiency of listed Chinese energy companies shows a V-shaped change trend without excluding environmental factors and random factors. Secondly, environmental factors and random factors are the primary factors to promote the green innovation efficiency of energy listed companies in China. Finally, after removing the interference of environmental factors and random factors, comprehensive efficiency of green innovation of the listed energy companies in China is relatively high and the distribution is relatively concentrated, but there is a downward trend during the research period.
\end{abstract}

\section{Introduction}

Energy enterprises play a very important role in China's economic development and assume the historical responsibility of realizing the beneficial development strategy of China as well. Relevant statistical results show that China's energy production and consumption enjoy sustaining growth. In 2019, the total energy production in China is 3.97 billion tons of standard coal, which increases by $5.3 \%$, compared to that in 2018. Meanwhile, total energy consumption in 2019 reaches 4.86 billion tons of standard coal, which increases by $4.7 \%$ compared to that in 2018 [1], as is shown in Figure 1.

However, with the increasing of the energy production and consumption in China, some problems related to ecological and environmental governance appear. Therefore, 2018 China Energy Development Report points out that China should continuously improve energy efficiency and develop towards high quality after basically meeting the demand of scale [2]. To retain the sustainable and high quality development of the energy industry, it is necessary to provide the enterprise innovation ability as soon as possible, improving the efficiency of green innovation of enterprises. In particular, it is beneficial to transform the energy companies from traditional extensive form to technology-oriented innovative type, allocate the resources, and promote the development of the green economy. Innovative development and green development are the key to transformation of energy enterprises. The green innovation of energy enterprises can break the constraints of resources and environment. Therefore, it is necessary to objectively evaluate the innovation efficiency of green technology in Chinese energy enterprises under the condition that the $R \& D$ investment of energy enterprises continues to increase and innovation resources are seriously insufficient.

In accordance with the EU's Horizon 2020 Framework Plan, technological innovation should be expressed as social hope, safe, and sustainable [3]. Therefore, in the process of sustainable development of enterprises, environmental responsibility and social responsibility are becoming as 


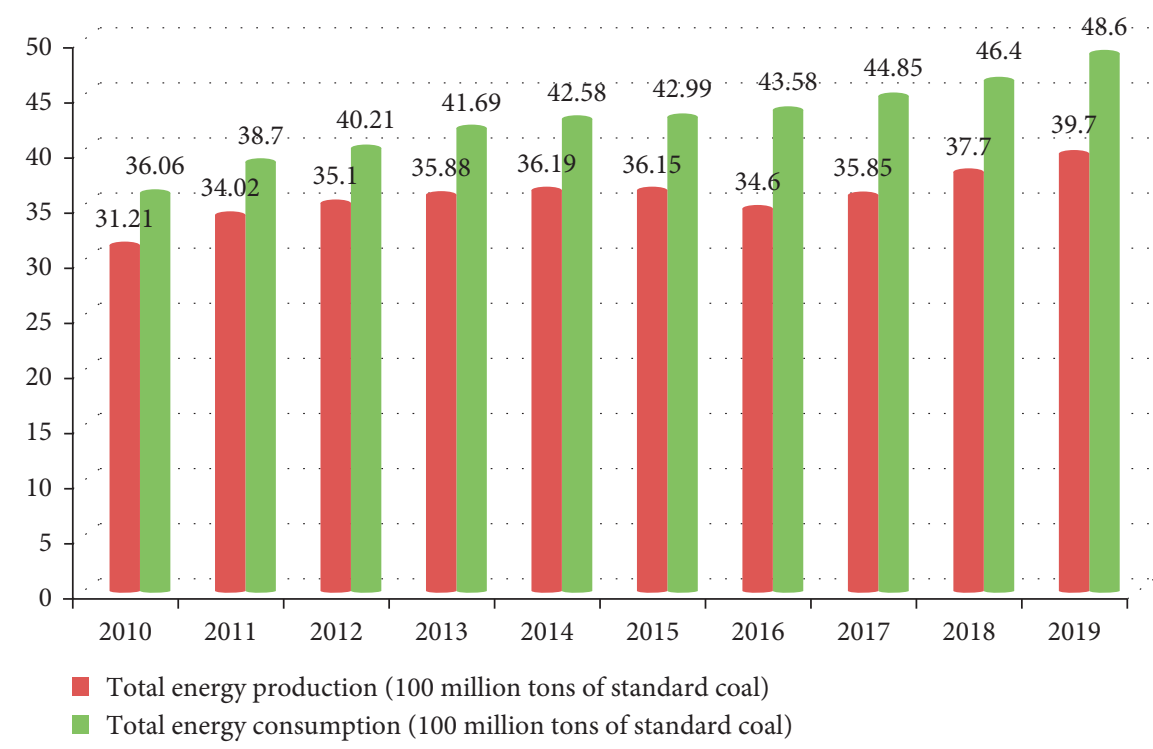

FIgURE 1: The total energy production and consumption from 2010 to 2019 in China.

important as corporate profits. These three factors constitute the triple bottom line (TLB) sustainable assessment framework and can evaluate the sustainable development of enterprises from a multidimensional perspective $[4,5]$. From a management perspective, efficiency refers to the ratio between the various inputs and outputs of an organization at a given time. Green innovation efficiency of energy enterprises from the perspective of triple bottom line also belongs to the category of input and output. That is to say, under the condition of limited investment in green innovation, energy enterprises should fulfill their economic responsibility, social responsibility, and environmental responsibility under the triple bottom line principle.

As the main body of sustainable innovation activities, it is necessary to discuss the efficiency of green innovation from the perspective of energy enterprises and from the perspective of the triple bottom line, but there is a lack of relevant research. At present, although some studies focus on the energy industry or the innovation efficiency of the energy industry, they do not focus the sustainable assessment framework and do not distinguish the internal characteristics of the energy industry, such as the green innovation efficiency of energy enterprises in different directions must be significantly different. In addition, it is difficult for existing research methods to effectively solve the problem of efficiency estimation. The window DEA method can distinguish the expected output from the nonexpected output, which is in line with the connotation of green innovation efficiency of energy enterprises.

Based on the above analysis, this paper conducts the research from the following aspects: at first, the efficiency differences of green innovation subjects can be analyzed in a more detailed way by taking listed energy companies as the research object, and the number of samples can be expanded to analyze the microforms of green innovation of energy in a broader scope. Second, from the perspective of the TLB theory, the window DEA model is constructed to comprehensively measure and analyze the economic, social, and environmental efficiency of China's listed energy companies in the process of green innovation, which is helpful to guide the sustainable development of energy companies. Finally, the three-stage DDF-DEA model adopted in this paper can effectively eliminate the impact of environmental factors and random errors on green innovation efficiency of listed energy companies so as to more truly reflect the actual level of green innovation efficiency of listed energy companies.

The study is arranged as follows: Section 2 discusses the literature on TBL and the evaluation of green innovation efficiency and puts forward the innovation points. Section 3 illustrates the window DEA three-stage model and the source of the empirical data set in details. Section 4 discusses the main findings of empirical analysis. The concluding section draws a conclusion and puts forward the direction of future study.

\section{Literature Review}

In recent years, the development of the energy industry has aroused people's concern about the ecological environment and pollution. At the same time, more and more countries and regions are paying attention to green development and sustainable innovation. Relevant studies mainly focus on the following aspects.

2.1. Concept of Green Innovation. At present, studies on the concept and connotation of green innovation are still in the exploration stage. The concept of green innovation originated from "sustainable development" and was first used in 1980 by the International Union for Conservation of Nature and Natural Resources in its World Conservation Strategy Report. Subsequently, "sustainable development" was defined as the deeds meeting current needs without compromising the ability of future generations to meet their own 
needs [6]. On this basis, the literatures related to sustainable innovation [7-10], ecological innovation [11-15], green innovation [16-21], and environmental innovation [22-25] are also gradually increasing. Since 2005, the international use of the concept of green innovation and related studies have increased rapidly. Driessen and Hillebrand argue that green innovation should not aim at reducing the environmental burden but should aim at producing significant environmental benefits [26]. Chen et al. believe that color innovation is equal to hardware or software innovation related to green products or green processes, including those related to energy conservation, pollution prevention, waste recycling, green product design, and enterprise environmental management technology [17]. According to Dai, the definition and connotation of "green innovation" in the academic community are unified, and "green" tends to be abused because of its over-conceptualization and vague connotation [27]. Liu sorted out the contents and basic conclusions of green innovation research and analyzed the rationality of the conclusions from the perspective of classification definition [28].

2.2. Green Innovation Efficiency. The research on green innovation efficiency mainly focuses on the evaluation of green innovation efficiency and its influencing factors, among which the input-output indicators are constructed by means of SFA [29-31], DEA [32-37], superefficiency DEA [38-41], and other related methods. There are also some studies that comprehensively evaluate the efficiency of green innovation through spatial econometrics [30] and entropy evaluation [42]. In terms of influencing factors of green innovation efficiency, it mainly focuses on macroenvironmental factors and microfactors. The macroenvironment mainly includes the institutional environment $[29,43]$, natural resources [44, 45], related industries [46], and related international trade relations [47-49]. At the microlevel, internal factors related to enterprises mainly include enterprise costs [50,51], enterprise goals, and social responsibilities $[52,53]$. It can be seen that empirical research on the efficiency of green innovation is varied according to different research problems.

2.3. Triple Bottom Line Theory. In 1997, Elkington first proposed the concept of the triple bottom line. He believed that in the field of responsibility, CSR can be divided into economic responsibility, environmental responsibility, and social responsibility $[5,54]$. The triple bottom line provides a framework for measuring business performance and has achieved economic, social, and environmental success [55]. At present, the triple bottom line has become an important part of enterprise and management decision and has been paid more and more attention in practice. The authors of [56-58] studied the importance of different enterprises or governments on profit, environmental, or social responsibility from the perspective of practical framework of sustainability. It shows that the triple bottom line is a practical research method to measure the enterprise's sustainable performance [59-61]. There are also some relevant studies that combine the triple bottom line theory with accounting theory to study the company's equity [62], annual report disclosure $[63,64]$, input-output [65], and other factors.

In short, the triple bottom line always takes economic, social, and environmental values as the main line, which provides a practical framework for the study of sustainable development.

\section{Research Design}

This paper mainly studies the energy green innovation efficiency of listed companies in China. In view of data availability, this paper selected the listed companies in Shanghai Stock Exchange and Shenzhen Stock Exchange as the research object.

A total of qualified 49 listed energy companies are screened, including Shenzhen Energy, Tunghsu Azure, Victory Stock, Nanjing Public, and Guangdong Electric Power Development. The research time range is from 2016 to 2018 , in order to ensure the timeliness of the research conclusions.

\subsection{Model Construction}

3.1.1. Traditional DEA Model. As a common method of efficiency measurement, DEA is widely used, but its shortcomings are also criticized. The shortcomings of the traditional DEA methods are reflected in the following aspects: first, the model assumes that decision units are homogeneous. However, the environment of each decisionmaking unit is different, so the decision-making unit cannot be completely homogeneous, and its efficiency is more or less affected by environmental factors and random factors. It is difficult for traditional DEA to eliminate the influence of the above factors, and the accuracy of efficiency value is negatively reflected. Second, the DEA model analyzes the efficiency value by constructing the frontier surface, which is different in different periods, resulting in the non-interperiod comparability of DEA efficiency [66].

In order to solve the above problems, scholars at home and abroad have revised the traditional DEA model appropriately. The three-stage DEA model proposed by Fried et al. well eliminates the influence of environmental factors and random factors on decision-making units, thus ensuring the homogeneity of decision-making units [67]. In order to make interpersonal comparison of DEA efficiency, Charnes et al. proposed a window DEA model, which can be used to analyze the evolution law of the efficiency value of the decision-making unit over time [68].

In this paper, panel data are used to study the green innovation efficiency of listed energy companies in China from the perspective of TBL. In order to eliminate the impact of environmental factors and random factors on efficiency measurement and analyze the dynamic evolution characteristics and influencing factors of green innovation efficiency, a three-stage window DEA model is constructed. 
3.1.2. Three-Stage Window DEA Model. The three-stage DEA model proposed by Fried et al. (2002) is mainly aimed at cross-sectional data. If panel data are used, the three-stage DEA model must be modified. In this context, the threestage window DEA model constructed in this paper is proposed. Its core idea is as follows: (1) The efficiency is evaluated by means of window DEA. (2) The relaxation variables are decomposed by the panel SFA model. (3) The panel management inefficiencies separation formula is used to adjust the decision unit. (4) The panel Tobit model is used to analyze the influencing factors of DEA efficiency of homogeneous decision-making unit. The details are listed as follows.

(1) The First Stage. In the first stage, the DEA-BBC model is adopted to measure the efficiency. Since the efficiency values of different fronts cannot be compared, this paper proposes to adopt window DEA to measure the dynamic efficiency of the decision-making unit. The window DEA model compares each decision-making unit with the frontier formed by fixed-width windows, so as to achieve the comparability of the efficiency of all decision-making units in time series.

(2) The Second Stage. Relaxation variables can reflect the initial low efficiency. In the second stage, this paper mainly focuses on relaxation variables and considers that relaxation variables are composed of environmental factors, management inefficiency, and statistical noise. By means of SFA regression, the relaxation variables are decomposed into the above three effects. Panel data model can better control individual heterogeneity, increase freedom, provide more information, have better statistical characteristics, and more accurate estimation results. Therefore, in the second stage, panel SFA regression is adopted in this paper:

$$
S_{\text {nit }}=f\left(Z_{\text {nit }} ; \beta_{\text {nit }}\right)+v_{\text {nit }}+\mu_{\text {nit }}, \quad i=1,2, \ldots, I, n=1,2, \ldots, N .
$$

where $S_{\text {nit }}$ is the relaxation value of the $n^{\text {th }}$ input in $i^{\text {th }}$ decision-making unit at the $t$ phase. $Z_{\text {nit }}$ is the environment variable, and $\beta_{\text {nit }}$ is the coefficient of the environment variable. $v_{\text {nit }}+\mu_{\text {nit }}$ is the mixed error term, $v_{\text {nit }}$ represents random interference, and $\mu_{\text {nit }}$ represents management inefficiency. It is generally assumed that the random disturbance term $v \sim N$ $\left(0, \sigma_{v}^{2}\right)$ obeys the standard normal distribution, and the management inefficiency term $\mu \sim N^{+}\left(0, \sigma_{\mu}^{2}\right)$ obeys the normal distribution truncated at zero.

According to the relationship between management inefficiency and time, the panel SFA can be divided into time-invariant model and time-varying recession model. The time-invariant model assumes that management inefficiency does not change with time and is expressed as $\mu_{i t}=\mu_{i}$. The corresponding formula for separating management inefficiency has changed as well:

$$
E\left(\mu_{i} \mid \varepsilon_{i}\right)=\mu_{* i}+\sigma_{*}\left[\frac{\phi\left(-\mu_{* i} / \sigma_{*}\right)}{1-\Phi\left(-\mu_{* i} / \sigma_{*}\right)}\right],
$$

where

$$
\begin{aligned}
\mu_{* i} & =\frac{T \sigma_{\mu}^{2} \overline{\varepsilon_{i}}}{\left(\sigma_{v}^{2}+T \sigma_{\mu}^{2}\right)}, \\
\sigma_{*}^{2} & =\frac{\sigma_{\mu}^{2} \sigma_{v}^{2}}{\left(\sigma_{v}^{2}+T \sigma_{\mu}^{2}\right)}, \\
\overline{\varepsilon_{i}} & =\frac{1}{T} \sum_{t} \varepsilon_{i t} .
\end{aligned}
$$

The time-varying recession model assumes that the management inefficiency changes with time. Battese and Coelli (1992) [69] assumed that $\mu_{i t}=\beta(t) \mu_{i}$ and $\beta(t)=\exp$ $\{-\eta(t-T)\}$ (where $T$ is the last period of decision-making units and $\eta$ is recession coefficient), and the corresponding management inefficiency separation formula is as follows:

$$
E\left(\mu_{i} \mid \varepsilon_{i}\right)=\mu_{* i}+\sigma_{*}\left[\frac{\phi\left(-\mu_{* i} / \sigma_{*}\right)}{1-\Phi\left(-\mu_{* i} / \sigma_{*}\right)}\right],
$$

where

$$
\begin{gathered}
\mu_{* i}=\frac{\left(\sum_{t} \beta_{t} \cdot \varepsilon_{i t}\right) \sigma_{\mu}^{2}}{\left(\sigma_{v}^{2}+\sigma_{\mu}^{2} \sum_{t} \beta_{t}^{2}\right)}, \\
\sigma_{*}^{2}=\frac{\sigma_{\mu}^{2} \sigma_{v}^{2}}{\left(\sigma_{v}^{2}+\sigma_{\mu}^{2} \sum_{t} \beta_{t}^{2}\right)} .
\end{gathered}
$$

The time-varying recession equation is used to verify the estimated $\eta$. If $\eta$ is not significant and is not 0 , then the timeinvariant model is used [70].

(3) The Third Stage. The adjusted input-output variables were analyzed by the DEA model again. Similarly, window DEA was used in this paper to obtain the efficiency value of the decision-making unit after eliminating environmental factors and random factors. At this time, the efficiency value conforms to the assumption of DEA homogeneity and is relatively objective and accurate.

3.1.3. Further Analysis. In order to make the constructed three-stage window DEA model in this paper easy to understand, the model is further analyzed in combination with Figure 2. As is shown in Figure 2, in the first stage, the window DEA model was used to calculate the green innovation efficiency of listed energy companies in China. The obtained DEA efficiency value did not conform to the assumption of homogeneity of decision units, so the efficiency value was not accurate. According to the research of Cummins et al. [66], there are three factors that affect the initial efficiency value, namely, environmental factors, management factors, and random factors. Due to the existence of environmental factors and random factors, decision units are not homogeneous, so it is necessary to eliminate environmental factors and random factors. In the second stage, with the help of SFA regression estimation parameters, environmental factors and random factors are 


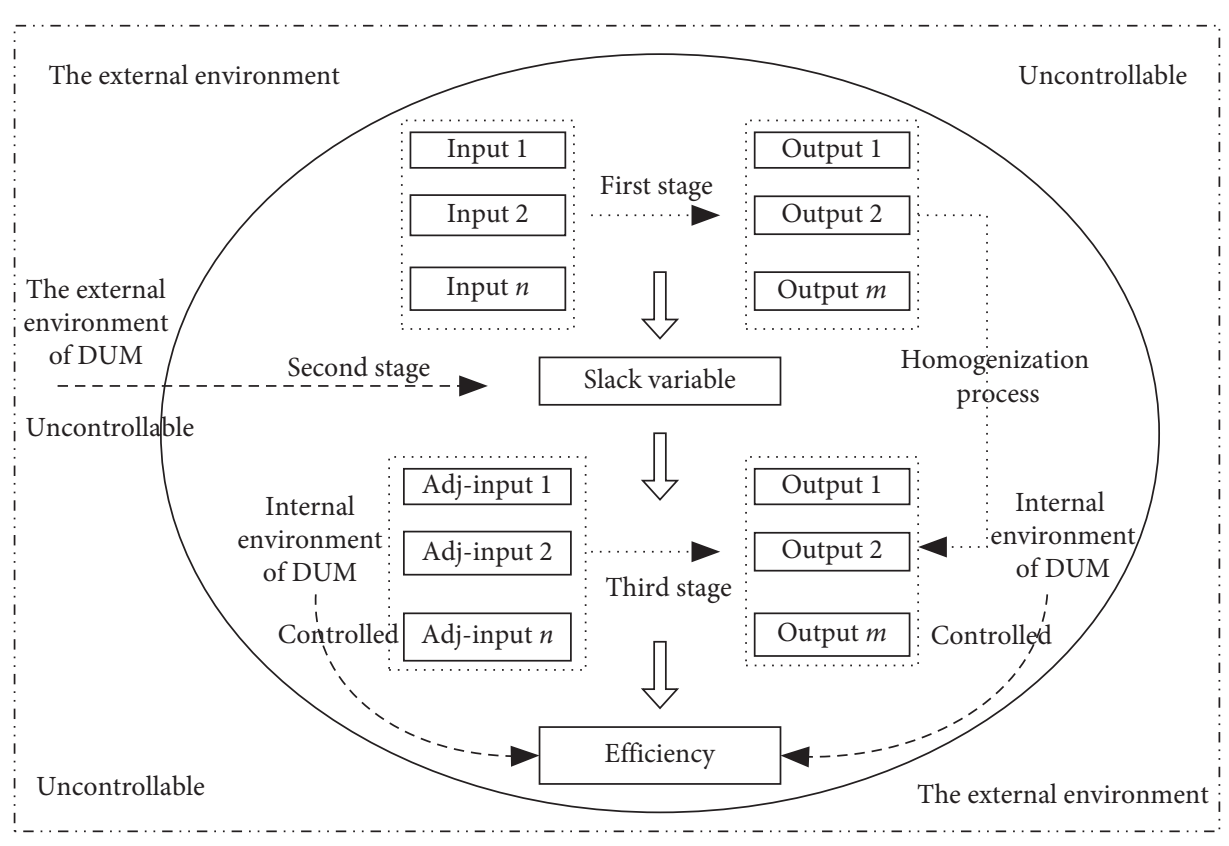

Figure 2: The three-stage window DEA schematic.

eliminated to obtain the adjusted input variables (or output variables). After the homogenization process in the second stage, the green innovation efficiency of listed Chinese energy companies in the third stage is relatively objective, and in theory, the efficiency value at this time is only affected by the internal management factors of the decision unit.

\subsection{Index Design}

3.2.1. Index of Innovation Input. As for innovation input, most scholars select indicators from the perspective of "human resources and property." For example, in their study on the efficiency of green innovation in China's heavily polluted industries, Fang et al. [71] focused on the selection of indicators from the two aspects of manpower and financial input, which are measured by the number of R\&D personnel and R\&D expenditure, respectively. Referring to the previous research literature, this paper selects the innovation input index of the three aspects of manpower input, financial input, and material input. For the manpower input, the index selected is the number of R\&D personnel; for the financial input, the index selected is R\&D expenditure; and for the material input, the index selected is fixed capital investment, and the fixed asset balance at the end of the year is taken as its proxy variable.

3.2.2. Index of Innovation Output. Under the background of $\mathrm{TBL}$, the green innovation output of listed energy companies in China includes economic efficiency output, social efficiency output, and environmental efficiency output. The economic benefit output of listed energy companies is measured by annual operating revenue, the social benefit output of listed energy companies is measured by patent quality and annual public welfare donation, and the environmental benefit output is measured by whether there is a positive environmental governance program.

3.2.3. Environmental Indicators of Innovation. The selection of innovative environmental indicators has an impact on the efficiency of decision-making unit (DMU), but there are factors that DMU cannot control as is shown below:

(1) Level of economic development: its impact on green innovation efficiency of listed Chinese energy companies is mainly reflected in two aspects. First, in regions with a high level of economic development, local governments pay more attention to scientific and technological innovation and will try their best to provide high-tech energy enterprises with a good research and policy environment, promote the transformation of scientific research results, maintain a high level of patent quality, and improve the social benefits of green innovation of listed energy companies. Second, in regions with a high level of economic development, the concept of green environment is more popular, which will improve the threshold of environmental access for enterprises, actively promote listed companies to improve the environmental governance program, and improve the environmental benefits of green innovation for listed energy companies. Per capita GDP better reflects the level of economic development, and this paper measures the level of regional economic development by per capita GDP.

(2) Openness: its impact on green innovation efficiency of listed energy companies in China is mainly reflected in two aspects. First, in recent years, the Chinese government has vigorously advocated 
scientific research to go abroad and carried out cooperative research with internationally renowned research institutions and enterprises, so as to enhance the scientific and technological innovation capacity of Chinese enterprises. Regions with a high degree of openness to the outside world are conducive to local enterprises to actively carry out foreign scientific research cooperation, promote the transformation of scientific research achievements of listed companies, and improve the social benefits of green innovation of listed energy companies. Second, in regions with high openness, the market economy is relatively active and the demand for energy products is relatively high, which helps us to improve the economic benefits of green innovation of listed energy companies. According to the conventional practice of referring to the literature at home and abroad, the level of opening up is measured by the proportion of total import and export volume to GDP, that is, the degree of dependence on foreign trade.

(3) Government support: its impact on green innovation efficiency is mainly reflected in two aspects. On the one hand, the inherent externality of green innovation of listed energy companies may bring high R\&D costs and risks to enterprise innovation, and appropriate government intervention and financial subsidies can make up for such defects and improve the social benefits of green innovation of listed energy companies. On the other hand, excessive government intervention may cause "crowding-out effect," which is not conducive to technological innovation of enterprises and reduces social benefits of green innovation of listed energy companies. Government subsidies can directly measure the government's support for listed energy companies. In order to eliminate the influence of scale, the ratio of government subsidies to total assets is used as a proxy indicator of government support.

The above definitions and data sources are summarized in Table 1.

3.3. Isotropy Test of Input-Output Indicators. In the window DEA model, the output and input indicators should have the same change trend; that is, there is no input index increase in the output index decreases, or there is no input index decrease with the input index increase. The Pearson correlation coefficient test method was used to investigate the isotropy of input-output indicators. The test results are shown in Table 2. As shown in the table, the correlation coefficients of the three input variables and four output variables selected in this paper are all positive, and all basically pass the significance test. It can be seen that the innovative input-output index of listed energy companies in China can be empirically studied with the three-stage window DEA model.

\section{Empirical Results and Analysis of Green Innovation Efficiency}

4.1. Window DEA Efficiency Measure in the First Stage. DEA-solver Pro5.0 software was used to calculate the green innovation efficiency (including comprehensive efficiency of green innovation, economic output efficiency of green innovation, social output efficiency of green innovation, and environmental output efficiency of green innovation) of 49 listed Chinese energy companies from 2016 to 2018 based on input orientation, assuming variable scale reward of DUM and setting window width $d=3$. Table 3 reports the measurement results of four kinds of efficiency. As shown in the table, the output efficiency value of green innovation economy is 0.478 in 2016, 0.451 in 2017, and 0.490 in 2018, showing a trend of decreasing first and then increasing. The output efficiency value of green innovation society was 0.351 in 2016, 0.234 in 2017, and 0.255 in 2018, showing a trend of decreasing first and then increasing. The output efficiency value of green innovation environment was 0.258 in 2016, 0.177 in 2017, and 0.191 in 2018, which also maintained the trend of decreasing first and then increasing. From the comprehensive efficiency of green innovation, it also shows the change trend of $\mathrm{V}$ shape due to the fact that there are a series of green innovation policies published during the period of "the $13^{\text {th }}$ Five-Year Plan." Especially in recent years, China continues to speed up the pace of the construction of an innovative country, adhering to the driving force of innovation and the coordinated development of green low carbon concept. Those factors work together to promote the listed energy companies to improve the innovation ability. However, as 2016 is the initial year of "the $13^{\text {th }}$ Five-Year Plan," provinces and cities introduced various policies for the energy enterprise green development. Under the pressure of the green development goals, the listed companies in the development and transformation on the green innovation has certain inadaptability, so there was a drop in the efficiency value in 2017, which is consistent with the actual situation in China's energy enterprises.

\subsection{Panel SFA Model Analysis in the Second Stage}

4.2.1. Model Selection. In order to investigate the temporal variation characteristics of green innovation efficiency of listed energy companies in China, the adjustment in the second stage should overcome the problem of heterogeneous frontier, so the panel stochastic frontier model with crosssectional comparability was selected. In addition, management inefficiency also needs to be focused in the paper, in the form of the approach put forward by Liu et al. [72]. The SFA equation model is estimated by time-varying recession, and coefficient $\eta$ is verified. If coefficient $\eta$ does not pass the significance test, then time-invariant model is suitable to estimate the parameters.

Table 4 shows the regression results of the panel SFA model. As shown in the table, firstly, it is necessary to observe whether the overall setting of the model is reasonable, mainly to see the LR unilateral percent. In the panel 
TABLE 1: Index system of green innovation efficiency measurement of listed energy companies in China.

\begin{tabular}{|c|c|c|c|}
\hline Index system & Index & Definition & Data resources \\
\hline \multirow{4}{*}{ Indicators of input } & Manpower input & R\&D personnel & Wind database \\
\hline & Finance input & R\&D expenditure (million) & Wind database \\
\hline & & The fixed asset balance at the & \\
\hline & Material input & $\begin{array}{l}\text { end of the year } \\
\text { (a hundred million) }\end{array}$ & Wind database \\
\hline \multirow{4}{*}{ Indicators of output } & Economic efficiency output & $\begin{array}{l}\text { Annual operating revenue } \\
\text { (a hundred million) }\end{array}$ & Wind database \\
\hline & & Patent quality (\%) & Wind database \\
\hline & Social efficiency output & $\begin{array}{l}\text { Annual public welfare } \\
\text { donation (a hundred) }\end{array}$ & Wind database \\
\hline & Environmental efficiency output & $\begin{array}{l}\text { A positive environmental governance } \\
\text { program (1 or } 0.1)\end{array}$ & Wind database \\
\hline \multirow{3}{*}{ Environment variables } & Level of economic development & Per capita GDP & Statistical yearbook \\
\hline & Openness & $\begin{array}{l}\text { The proportion of total import and } \\
\text { export volume to GDP }\end{array}$ & Statistical yearbook \\
\hline & Government support & $\begin{array}{l}\text { The ratio of government subsidies } \\
\text { to total assets }\end{array}$ & Wind database \\
\hline
\end{tabular}

Table 2: Pearson test of green innovation input-output index of listed energy companies in China.

\begin{tabular}{lcccc}
\hline Index & Annual operating revenue & Patent quality & $\begin{array}{c}\text { Annual public } \\
\text { welfare donation }\end{array}$ & $\begin{array}{c}\text { A positive environmental } \\
\text { governance program }\end{array}$ \\
\hline Manpower & $0.769^{* * *}$ & $0.073^{*}$ & $0.442^{* * *}$ & 0.108 \\
input & $(0.0001)$ & $(0.037)$ & $(0.0001)$ & $(0.194)$ \\
\hline Finance input & $0.730^{* * *}$ & $0.077^{* *}$ & $0.507^{* * *}$ & $0.117^{*}$ \\
& $(0.0001)$ & $(0.014)$ & $(0.0001)$ & $(0.095)$ \\
\hline \multirow{2}{*}{ Material input } & $0.730^{* * *}$ & $0.077^{* *}$ & $0.563^{* * *}$ & $0.217^{* * *}$ \\
& $(0.0001)$ & $(0.032)$ & $(0.0001)$ & $(0.0001)$ \\
\hline
\end{tabular}

${ }^{* * *},{ }^{* *}$, and ${ }^{*}$ represent the significance of $1 \%, 5 \%$, and $10 \%$, respectively. The numbers in parentheses are the $P$ value of the estimated value of the corresponding parameters.

TABLE 3: Green innovation efficiency of China's listed energy companies during 2016-2018 (stage I).

\begin{tabular}{ccccc}
\hline & $\begin{array}{c}\text { Economic output efficiency of } \\
\text { green innovation }\end{array}$ & $\begin{array}{c}\text { Social output efficiency of } \\
\text { green innovation }\end{array}$ & $\begin{array}{c}\text { Environmental output efficiency of } \\
\text { green innovation }\end{array}$ & $\begin{array}{c}\text { Comprehensive efficiency of } \\
\text { green innovation }\end{array}$ \\
\hline 2016 & 0.478 & 0.351 & 0.258 & 0.540 \\
2017 & 0.451 & 0.234 & 0.177 & 0.486 \\
2018 & 0.490 & 0.255 & 0.191 & 0.530 \\
\hline
\end{tabular}

TABle 4: Panel SFA regression results of the second stage.

\begin{tabular}{lccc}
\hline Relaxation variable coefficient & Manpower input (model 1) & Financial input (model 2) & Material input (model 3) \\
\hline Constant term & $32.32^{* * *}(0.0001)$ & $14.43^{* * *}(0.0001)$ & $21.25^{* * *}(0.0001)$ \\
Level of economic development & $-0.182^{* * *}(0.0001)$ & $0.132^{* * *}(0.0001)$ & $0.075^{* *}(0.019)$ \\
Openness & $-2.439^{* * *}(0.0001)$ & $-3.274^{* * *}(0.0001)$ & $16.285(0.838)$ \\
Government support & $12.072^{* * *}(0.007)$ & $1.134^{* *}(0.035)$ & $6.208^{* *}(0.021)$ \\
$\eta$ & 0 & $0.005^{* * *}(0.0001)$ & $0.009^{* * *}(0.0001)$ \\
$\sigma$ & 88120.00 & 9835.00 & 24828.00 \\
$\gamma$ & 0.574 & 0.393 & 0.999 \\
LR unilateral error & $71.32^{* * *}$ & $48.35^{* * *}$ & $54.35^{* * *}$ \\
TI or TVD & Constant coefficient model & Time-varying recession model & Time-varying recession model
\end{tabular}

***, **, and * represent the significance of $1 \%, 5 \%$, and $10 \%$, respectively. The numbers in parentheses are the $P$ values of the estimated values of the corresponding parameters.

SFA model with the relaxation variables of three input indexes as the explained variables, LR unilateral percentages are $71.32,48.35$, and 54.35, respectively, and all of them pass the test criteria of $1 \%$ significance level. Thus, the panel SFA model constructed in this paper is reasonable. Secondly, $\gamma$ statistics of model 1 is $0.574, \gamma$ statistics for model 2 is 0.393 , 
and $\gamma$ statistics for model 3 is 0.999 , which means $\gamma$ statistics of three models are still in the range $0 \sim 1$, and all pass the $1 \%$ level of significance test. It shows that the energy green innovation efficiency in the first stage is influenced by environmental factors and random factors mutual influence. Finally, $\eta$ statistics for model 1 is $0, \eta$ statistics for model 2 is 0.005 , and $\eta$ statistics for model 3 is 0.009 , which means $\eta$ statistics pass the significance test. This shows that the management inefficiency term of the labor input equation is constant, so the constant coefficient model should be adopted. Management inefficiency of model 2 and model 3 has typical time-varying characteristics, and the timevarying recession model should be adopted. Overall, the panel SFA model set up in stage 2 is reasonable.

\subsubsection{The Impact of Environmental Factors on the Green Innovation Efficiency}

(1) Level of Economic Development. The regression coefficient of economic development level of the slack variable of manpower input is negative, and it passes the test of $1 \%$ significance level. The regression coefficients of financial input and material input relaxation variables are both positive and pass the test of significance level of $1 \%$ and $5 \%$, respectively. The regression results show that the economic development level has different effects on different green innovation input variables. First of all, the impact on human resources investment, the higher the level of regional economic development, the more to absorb outstanding scientific research and innovation talent, so the innovation ability of scientific research team is stronger, making full use of their talents and reducing the redundant investment of scientific research personnel. Second, the higher the level of regional economic development, the more the attention will be paid to technological innovation and the concept of green development, and a large amount of R\&D funds will be invested in green innovation research projects. However, research projects are difficult to reflect the results in a short term, and there is a certain lag period, resulting in redundant financial investment. Finally, the impact on material input, economic development level of the region, and the investment scale is relatively large and easy to cause investment redundancy.
(2) Openness. The regression coefficients of external openness to the relaxation variables of manpower input and financial input was negative, and both passed the test of $1 \%$ significance level. The regression coefficient of the material input relaxation variable did not pass the test of significance level. It can be seen that the degree of openness to the outside world has a positive impact on green innovation efficiency of listed energy companies in China mainly by influencing human and financial input. The main reason is that the higher the degree of openness to the outside world is, the more the exchanges and cooperation between the listed energy companies and foreign scientific research institutions will be, which can ensure the frontier, practicability, and value of scientific research activities, reduce the redundancy of human resources input and scientific research project establishment, and improve the efficiency of scientific and technological innovation.

(3) Government Supports. The regression coefficients of government support for the relaxation variables of human input, financial input, and material input are all positive and pass the test of significance levels of $1 \%, 5 \%$, and $5 \%$, respectively. This shows that in the green innovation link of the listed energy companies in China, government intervention is more obvious than the scope of "appropriate intervention," which leads to redundant investment of researchers, redundant investment of research project funds, and redundant investment of research equipment, which has a negative impact on the green innovation of China's listed energy companies.

Due to the interference of environmental factors and random factors, 49 listed energy companies did not conform to the assumption of homogeneity, resulting in the great defects of the green innovation efficiency estimated in the first stage. In order to eliminate environmental factors and random factors, this paper uses the above management inefficiency separation formula to decompose environmental factors and random factors and adopts the following formula to put the decision unit in the same external environment, so as to achieve the assumption of homogeneity:

$$
X_{n i}^{A}=X_{n i}+\left[\max \left(f\left(Z_{i} ; \hat{\beta}_{n}\right)\right)-f\left(Z_{i} ; \hat{\beta}_{n}\right)\right]+\left[\max \left(v_{n i}\right)-v_{n i}\right], \quad i=1,2, \ldots, I, n=1,2, \ldots, N
$$

where $X_{n i}^{A}$ is the input after the adjustment, $X_{n i}$ is the input before the adjustment, $\left[\max \left(f\left(Z_{i} ; \hat{\beta}_{n}\right)\right)-f\left(Z_{i} ; \hat{\beta}_{n}\right)\right]$ are the external environmental factors, and $\left[\max \left(v_{n i}\right)-v_{n i}\right]$ puts all decision units at the same level of luck.

\subsection{Window DEA Efficiency Analysis in the Third Stage.}

Table 5 shows the values of green innovation economic output efficiency, social output efficiency, environmental output efficiency, and comprehensive efficiency of listed energy companies in China. As shown in the table, green innovations of listed energy companies based on the TBL are different and vary greatly. 
TABLE 5: Green innovation efficiency value of China's listed energy companies from 2016 to 2018.

\begin{tabular}{|c|c|c|c|c|c|c|c|c|c|c|c|c|c|}
\hline \multirow[t]{2}{*}{ Company name } & \multirow[t]{2}{*}{ Stock code } & \multicolumn{3}{|c|}{$\begin{array}{l}\text { Economic output } \\
\text { efficiency }\end{array}$} & \multicolumn{3}{|c|}{$\begin{array}{l}\text { Social output } \\
\text { efficiency }\end{array}$} & \multicolumn{3}{|c|}{$\begin{array}{l}\text { Environmental } \\
\text { output efficiency }\end{array}$} & \multicolumn{3}{|c|}{$\begin{array}{l}\text { Comprehensive } \\
\text { efficiency }\end{array}$} \\
\hline & & 2016 & 2017 & 2018 & 2016 & 2017 & 2018 & 2016 & 2017 & 2018 & 2016 & 2017 & 2018 \\
\hline Shenzhen Energy & 000027 & 0.689 & 0.891 & 0.894 & 0.368 & 0.396 & 0.335 & 0.297 & 0.323 & 0.303 & 0.706 & 0.946 & 0.933 \\
\hline Tunghsu Azure & 000040 & 1.000 & 0.954 & 0.836 & 0.984 & 0.693 & 0.878 & 0.984 & 0.534 & 0.445 & 1.000 & 1.000 & 0.988 \\
\hline Victory Stock & 000407 & 0.994 & 1.000 & 1.000 & 0.995 & 0.972 & 0.921 & 0.987 & 0.963 & 0.921 & 1.000 & 1.000 & 1.000 \\
\hline Nanjing Utilities & 000421 & 1.000 & 1.000 & 1.000 & 1.000 & 1.000 & 1.000 & 1.000 & 1.000 & 1.000 & 1.000 & 1.000 & 1.000 \\
\hline Guangdong Electric Power Development & 000539 & 0.911 & 0.950 & 0.976 & 0.249 & 0.314 & 0.255 & 0.191 & 0.167 & 0.167 & 0.912 & 0.980 & 0.978 \\
\hline Wanneng Power & 000543 & 1.000 & 1.000 & 1.000 & 0.438 & 0.389 & 0.349 & 0.435 & 0.389 & 0.349 & 1.000 & 1.000 & 1.000 \\
\hline Soar Energy & 000591 & 1.000 & 1.000 & 0.989 & 1.000 & 0.794 & 0.807 & 1.000 & 0.792 & 0.803 & 1.000 & 1.000 & 1.000 \\
\hline Datong Gas & 000593 & 1.000 & 1.000 & 0.973 & 1.000 & 1.000 & 1.000 & 1.000 & 1.000 & 0.971 & 1.000 & 1.000 & 1.000 \\
\hline Xiongrong Envir & 000598 & 1.000 & 1.000 & 0.930 & 1.000 & 0.995 & 0.867 & 1.000 & 1.000 & 1.000 & 1.000 & 1.000 & 1.000 \\
\hline Jiantou Energy & 000600 & 0.786 & 0.808 & 1.000 & 0.602 & 0.602 & 1.000 & 0.455 & 0.433 & 1.000 & 1.000 & 1.000 & 1.000 \\
\hline Shaoneng Stock & 000601 & 1.000 & 1.000 & 0.997 & 0.984 & 0.977 & 1.000 & 0.964 & 0.958 & 0.960 & 1.000 & 1.000 & 1.000 \\
\hline Bohai Stock & 000605 & 1.000 & 1.000 & 0.978 & 1.000 & 1.000 & 0.984 & 1.000 & 1.000 & .978 & 1.000 & 1.000 & 0.991 \\
\hline Jinhong Stock & 000669 & 0.905 & 1.000 & 1.000 & 0.888 & 0.965 & 0.945 & 0.887 & 0.960 & 0.943 & 0.905 & 1.000 & 1.000 \\
\hline Zhongshan Utilities & 000685 & 0.994 & 0.992 & 0.910 & 0.999 & 1.000 & 1.000 & 0.994 & 0.992 & 0.910 & 1.000 & 1.000 & 1.000 \\
\hline Xinneng Taishan & 000720 & 1.000 & 1.000 & 1.000 & 1.000 & 1.000 & 1.000 & 1.000 & 1.000 & 1.000 & 1.000 & 1.000 & 1.000 \\
\hline Zhangze Power & 000767 & 0.998 & 1.000 & 0.974 & 0.500 & 0.438 & 0.303 & 0.731 & 0.616 & 0.532 & 1.000 & 1.000 & 0.981 \\
\hline Yinxing Energy & 000862 & 1.000 & 0.995 & 1.000 & 1.000 & 0.995 & 1.000 & 1.000 & 0.995 & 1.000 & 1.000 & 0.996 & 1.000 \\
\hline Hubei Power & 000883 & 0.799 & 0.866 & 0.840 & 0.683 & 0.567 & 0.524 & 0.394 & 0.355 & 0.320 & 0.978 & 0.960 & 0.971 \\
\hline Gedong Power & 000993 & 1.000 & 1.000 & 0.972 & 1.000 & 1.000 & 1.000 & 1.000 & 1.000 & 0.972 & 1.000 & 1.000 & 1.000 \\
\hline Shanxi Gas & 002267 & 1.000 & 0.975 & 0.967 & 0.591 & 0.615 & 0.557 & 0.591 & 0.603 & 0.489 & 1.000 & 0.986 & 0.991 \\
\hline ZFET & 002479 & 1.000 & 1.000 & 0.976 & 0.969 & 0.976 & 0.958 & 0.965 & 0.971 & 0.952 & 1.000 & 1.000 & 0.977 \\
\hline Jiangsu Guoxin & 2608 & 1.000 & 1.000 & 0.987 & 1.000 & 1.000 & 0.224 & 1.000 & 1.000 & 0.219 & 1.000 & 1.000 & 0.988 \\
\hline Tianhao & 32 & 1.000 & 0.994 & 0.855 & 1.000 & 1.000 & 0.876 & 1.000 & 0.994 & 0.855 & 1.000 & 1.000 & 0.884 \\
\hline Siser & -5 & 0.843 & 0.773 & 0.679 & 0.999 & 1.000 & 1.000 & 0.869 & 0.805 & 0.751 & 0.999 & & 1.000 \\
\hline Shou & o & 0.891 & 0.866 & 0.911 & 0.589 & 0.568 & 0.461 & 0.601 & 0.651 & 0.658 & 1.000 & 1.000 & 1.000 \\
\hline Huan & 0011 & 1.000 & 1.000 & 1.000 & 0.109 & 0.131 & 0.186 & 0.128 & 0.117 & 0.117 & 1.000 & 1.000 & 1.000 \\
\hline Shang & 00021 & 1.000 & 1.000 & 1.000 & 1.000 & 1.000 & 1.000 & 1.000 & 1.000 & 1.000 & 1.000 & 1.000 & 1.000 \\
\hline Guan & 600098 & 0.944 & 1.000 & 0.975 & 0.262 & 0.357 & 0.471 & 0.207 & 0.203 & 0.178 & 0.944 & 1.000 & 0.994 \\
\hline Liann & 0167 & 1.000 & 0.950 & 1.000 & 1.000 & 0.936 & 1.000 & 1.000 & 0.936 & 1.000 & 0.873 & 0.964 & 1.000 \\
\hline Wuhan Stock & 600168 & 1.000 & 0.987 & 1.000 & 1.000 & 0.989 & 1.000 & 1.000 & 0.987 & 1.000 & 0.732 & 1.000 & 1.000 \\
\hline Guozhong Water Supplies & 600187 & 0.999 & 1.000 & 1.000 & 0.999 & 1.000 & 1.000 & 0.999 & 1.000 & 1.000 & 0.999 & 1.000 & 1.000 \\
\hline Ancai Hi-tech & 600207 & 1.000 & 1.000 & 0.476 & 1.000 & 1.000 & 0.515 & 1.000 & 1.000 & 0.478 & 0.783 & 1.000 & 0.515 \\
\hline Chuangchun Gas & 600333 & 0.862 & 0.888 & 1.000 & 1.000 & 0.939 & 1.000 & 0.862 & 0.888 & 1.000 & 0.791 & 0.950 & 1.000 \\
\hline Hongcheng Water & 600461 & 1.000 & 1.000 & 1.000 & 1.000 & 1.000 & 1.000 & 1.000 & 1.000 & 1.000 & 0.799 & 1.000 & 1.000 \\
\hline Funeng Stock & 600483 & 1.000 & 0.997 & 1.000 & 0.804 & 0.775 & 0.619 & 0.793 & 0.751 & 0.611 & 0.807 & 1.000 & 1.000 \\
\hline Tianfu Energy & 600509 & 0.985 & 1.000 & 1.000 & 1.000 & 1.000 & 1.000 & 0.921 & 0.921 & 0.898 & 0.815 & 1.000 & 1.000 \\
\hline Shenneng Stock & 600642 & 1.000 & 1.000 & 1.000 & 1.000 & 1.000 & 1.000 & 1.000 & 1.000 & 1.000 & 0.823 & 1.000 & 1.000 \\
\hline Chuantou Energy & 0674 & 0.992 & 0.886 & 0.607 & 1.000 & 1.000 & 0.677 & 0.992 & 0.886 & 0.607 & 0.831 & 1.000 & 0.680 \\
\hline Huayin Power & 600744 & 0.943 & 0.917 & 0.792 & 0.724 & 0.686 & 0.386 & 0.660 & 0.584 & 0.375 & 0.988 & 0.974 & 0.798 \\
\hline State Power & 0795 & 1.000 & 0.964 & 0.942 & 0.110 & 0.284 & 0.361 & 0.142 & 0.172 & 0.151 & 0.736 & 1.000 & 1.000 \\
\hline Capita & 00874 & 1.000 & 1.000 & 1.000 & 1.000 & 1.000 & 1.000 & 1.000 & 1.000 & 1.000 & 0.981 & 1.000 & 1.000 \\
\hline Huajing Power Holdings & 600886 & 0.896 & 0.939 & 0.881 & 0.315 & 0.210 & 0.140 & 0.211 & 0.244 & 0.136 & 0.907 & 0.967 & 0.881 \\
\hline Yangt/ & 600900 & 1.000 & 1.000 & 0.877 & 0.124 & 1.000 & 0.299 & 0.211 & 0.212 & 0.189 & 0.732 & 1.000 & 0.881 \\
\hline Chon & 0917 & 0.824 & 0.841 & 0.252 & 0.930 & 0.889 & 0.224 & 0.618 & 0.615 & 0.168 & 0.824 & 1.000 & 0.288 \\
\hline Shenzhen Gas & 1139 & 0.937 & 0.928 & 0.496 & 0.554 & 0.482 & 0.232 & 0.503 & 0.392 & 0.183 & 0.971 & 0.955 & 0.502 \\
\hline Chongqing Wate & 601158 & 0.675 & 0.688 & 0.225 & 1.000 & 1.000 & 0.247 & 0.612 & 0.629 & 0.181 & 0.835 & 1.000 & 0.281 \\
\hline Jiangnan Water Supplies & 601199 & 1.000 & 0.983 & 0.668 & 1.000 & 0.983 & 0.668 & 1.000 & 0.983 & 0.668 & 0.743 & 0.983 & 0.668 \\
\hline China Nuclear Power & 601985 & 0.980 & 0.982 & 0.491 & 0.218 & 0.173 & 0.122 & 0.260 & 0.239 & 0.117 & 0.725 & 0.996 & 0.511 \\
\hline Datang Power & 601991 & 0.915 & 0.987 & 1.000 & 0.141 & 0.113 & 0.164 & 0.136 & 0.117 & 0.117 & 0.938 & 0.998 & 1.000 \\
\hline
\end{tabular}

4.3.1. Analysis on Economic Output Efficiency of Green Innovation. Figure 3 shows the efficiency of green innovation economic output of China's listed energy companies from 2016 to 2018. At the national level, the efficiency value of green innovation economic output of China's listed energy companies in 2016 was 0.954 . In 2017, the output efficiency value of green innovation economy was 0.959 , basically unchanged compared with the previous year. In 2018, the output efficiency value of green innovation economy was 0.884 , showing a significant decline. This is basically consistent with the actual situation of the development of the energy industry at home and abroad. In particular, the global energy intensity growth in 2018 fell to the lowest level in nearly a decade, indicating that the growth of global energy use efficiency slowed down, directly affecting the global and China's energy economic output. Certainly, this is related to the country's strong promotion of green development. Some interest groups related to listed energy companies have some resistance to this, which will directly affect the economic output of listed energy companies.

By region, in 2016, the efficiency value of green innovation economic output of listed energy companies in the eastern region was 0.996 , the efficiency value of green 


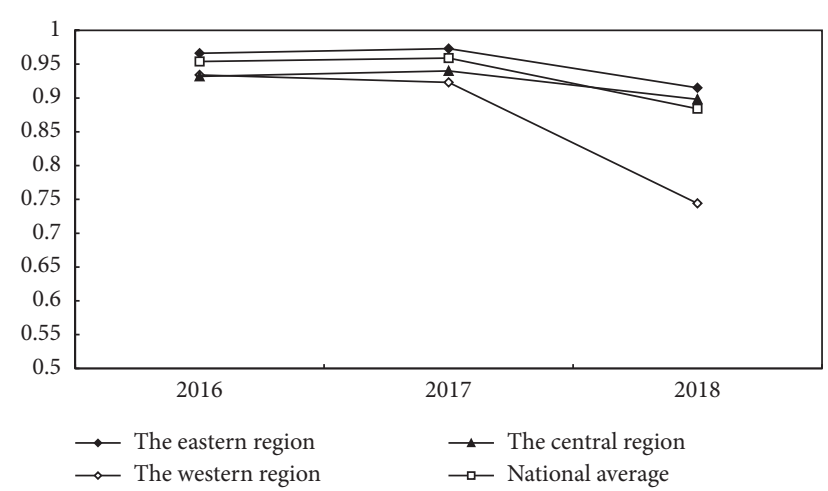

FIGURE 3: Green innovation economic output efficiency of listed energy companies in China from 2016 to 2018.

innovation economic output in the central region was 0.932 , and the efficiency value of green innovation economic output in the western region was 0.934 . In 2017, the output efficiency value of green innovation economy in the eastern region was 0.973 , the output efficiency value of green innovation economy in the central region was 0.940 , and the output efficiency value of green innovation economy in the western region was 0.923 . In 2018, the output efficiency value of green innovation economy in the eastern region was 0.915, the output efficiency value of green innovation economy in the central region was 0.898 , and the output efficiency value of green innovation economy in the western region was 0.744 , all of which showed a relatively obvious trend of efficiency decline, and the output efficiency of green innovation economy in the western region was the most obvious decline. From the final value of output efficiency of green innovation economy, it shows that "eastern > central > western," which is consistent with the traditional economic pattern. This benefits from the geographical environment and economic development level of eastern regions and central regions. The listed energy companies started their green innovation early and are characterized with high technology and rich innovation talented pool, which is beneficial to energy organization innovation activities of listed companies, and can effectively promote the efficiency of economic output. In addition, governments in the eastern and central regions invest more on R\&D equipment and R\&D funds, which will also improve the efficiency of enterprises' innovative economic output.

4.3.2. Analysis on Social Output Efficiency of Green Innovation. Figure 4 shows the social output efficiency of green innovation of China's listed energy companies from 2016 to 2018. At the national level, the social output efficiency value of green innovation in 2016 was 0.778 . In 2017, the output efficiency of green innovation society was 0.780 , basically unchanged compared with the previous year. In 2018 , the output efficiency value of the green innovation economy was 0.685 , showing a significant downward trend. The main reason for the decline of green innovation output efficiency in 2018 is that although the number of patents of most listed energy companies has been increasing year by year, the quality has declined, leading to the fact that the output decreases when the input increases year by year. Relevant data show that the licensing rate of invention patents in China has dropped from 56.8 percent in 2015 to 40 percent in 2019, which also reflects the low pass rate and low quality of patents in China.

By region, in 2016, the social output efficiency values of green innovation of listed energy companies in the eastern region, the central region, and the western region were $0.739,0.772$, and 0.940 , respectively, which shows the opposite of the traditional economic pattern "eastern > central > western." In 2017, the social output efficiency values of green innovation in the eastern region, the central region, and western region were $0.753,0.734$, and 0.937 , respectively. In 2018, the social output efficiency values of green innovation in the eastern region, central region, and western region were $0.685,0.675$, and 0.697 , respectively.

Overall, the green innovation social output efficiency in the western region is higher than that in the central region, which is in turn higher than that in the eastern region, while the green innovation output efficiency of the distribution is on the contrary. It can be seen that the listed energy companies in eastern areas are better at creating economic benefits, and the companies in the central areas and western areas are better at creating social benefits. This is because the western region has relatively little input, but its social output is relatively high. From 2016 to 2018, the green innovation social output efficiency of Datong Gas, Hongcheng Water Industry, Tianfu Energy, and other companies is 1, achieving the effectiveness requirement of DEA. These enterprises basically reach a stable state in terms of social output. In addition, although Yinxing Energy, Chongqing Water, and Chongqing Gas are all reaching the effectiveness requirement of DEA, the social output efficiency of green innovation in most years is 1 . Therefore, listed energy companies in western China have strong ability in creating social benefits. For the central and eastern regions, firstly, there are more listed energy companies. Individual companies such as Shenzhen Energy, Yuedian Power A, Wanneng Power, Zhangze Power, China Nuclear Power, Datang Power Generation and other companies have large investment, resulting in social output The annual average efficiency is below 0.5 . For example, Datang Power is only approximately 0.14 , which has great impact on the comprehensive social output in the central eastern areas. In addition, influenced by government innovation policy, it appeared a downward trend in 2018.

\subsubsection{Analysis on Environmental Output Efficiency of Green} Innovation. Figure 5 shows the output efficiency of green innovation environment of listed energy companies in China from 2016 to 2018. At the national level, the output efficiencies of green innovation environment of China's listed energy companies were $0.747,0.722$, and 0.646 in 2016, 2017, and 2018, respectively, showing an obvious downward trend. The main reason for the decline in 2018 is that the industry lagged behind the market due to the combined 


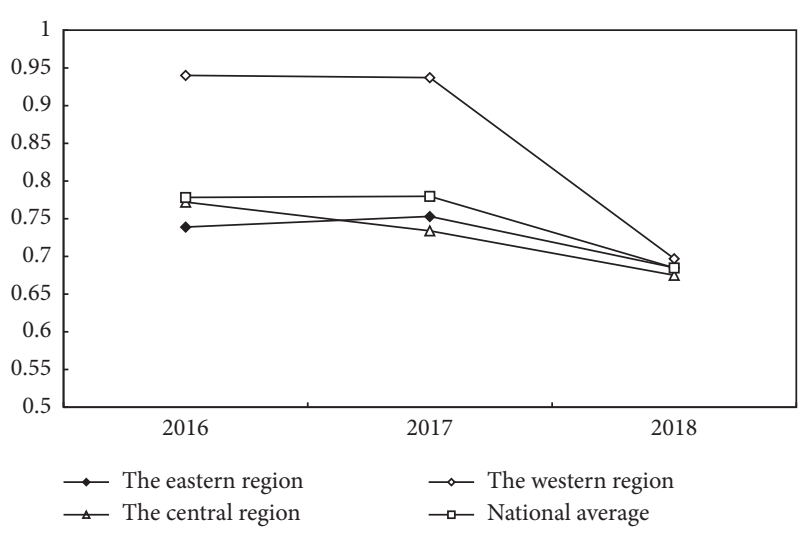

Figure 4: Green innovation social output efficiency of listed energy companies in China from 2016 to 2018.

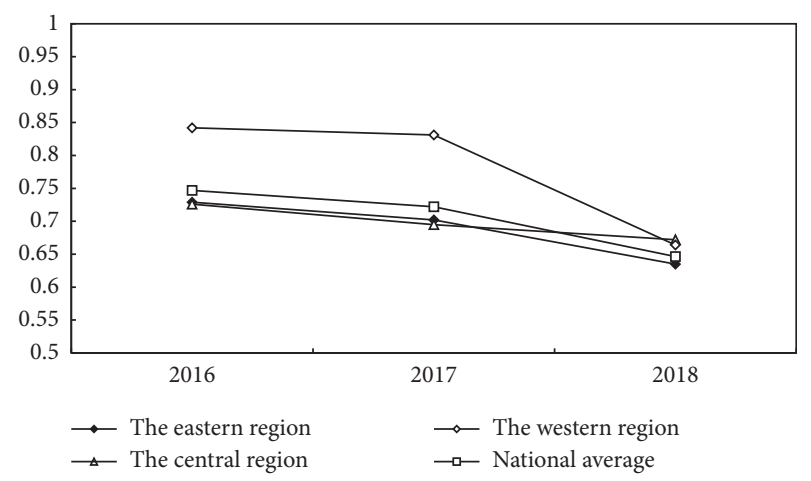

FIGURE 5: Environmental output efficiency of green innovation of listed energy companies in China from 2016 to 2018.

effect of macropolicy adjustment in 2016 and 2017, increased downward pressure on the economy, tight capital, increased environmental regulation, and the risks of enterprises. Aiming at these problems, the Ministry of Ecological Environment issued "Ecological Environmental Monitoring Quality Supervision and Inspection Action Plan (2018-2020)" in August 2018, which requires that by 2020, the enterprise needs to constantly improve the quality of ecological environment monitoring data security responsibility system, crack down on inappropriate behavior intervention ecological environment monitoring, effectively curb the ecological environment monitoring institutions and units data falsification problems, and ensure the monitoring data of true, accurate and objective.

By region, the output efficiency value of green innovation environment of listed energy companies in the eastern region, the central region and the western region were 0.729 , 0.726 and 0.842 in 2016, 2017, and 2018 respectively. The following trend is observed: "western > eastern > central". In 2017, the environmental output efficiency values of green innovation in the eastern region, the central region, and the western region were $0.702,0.695$, and 0.831 respectively. In 2018, the environmental output efficiency values of green innovation in the eastern region, the central region, and the western region were $0.635,0.672$, and 0.664 respectively, all of which showed an obvious trend of efficiency decline, and the most obvious change was in the western region. On the whole, environmental output efficiency of green innovation in the central region is relatively stable, and the environmental output efficiency of green innovation in the eastern and western regions fluctuates significantly. This is mainly due to the relatively small investment in the western region as a whole, which in turn directly affects the efficiency of its environmental output value. The eastern region, with the guide of national policies, constantly introduced effective environmental policies, so that the environmental management plans of the listed companies have positive effects as well, but its overall higher investment makes its final environment output lower than that in the western region. Moreover, there are more listed energy companies in the eastern region, and those companies with lower efficiency values directly affect the overall level of efficiency. Therefore, based on the different regional characteristics of the eastern region, central region, and western region, the government should formulate corresponding environmental governance policies for listed energy companies.

4.3.4. Analysis on Comprehensive Efficiency of Green Innovation. Figure 6 shows the comprehensive efficiency of green innovation of listed energy companies in China from 2016 to 2018. From a national perspective, the comprehensive efficiency values of green innovation of China's listed energy companies were $0.985,0.993$, and 0.912 in 2016, 2017, and 2018 respectively, showing an obvious downward trend. This is mainly affected by the global energy environment as a whole in 2018. At the same time, the macropolicy adjustment in China and increasing economic downward pressure makes the green innovation output efficiency of the listed energy company decline in 2018, which eventually led to a downward trend of the comprehensive efficiency value. However, it should be noticed that the overall comprehensive efficiency value is still high, which, from a certain extent, shows the scale effect of listed energy companies in the field of green innovation development gradually formed, and it is improving as well.

By region, in 2016, the comprehensive efficiency values of green innovation of listed energy companies in the eastern region, the central region, and the western region were 0.978 , 0.996 , and 1 , which shows the "western $>$ central $>$ eastern" pattern. In 2017, the comprehensive efficiency values of green innovation of listed energy companies in the eastern region, the central region, and the western region were 0.993 , 0.987, and 0.998. In 2018, the comprehensive efficiency values of green innovation of listed energy companies in the eastern region, the central region, and the western region were $0.943,0.918$, and 0.778 . This shows that there is a distinct regional characteristic for the green innovation energy efficiency of the listed energy companies in China. The comprehensive green innovation efficiency value of the western region from 2016 to 2017 is significantly higher than those of central and eastern regions, which shows the effectiveness of pairing assistance policies in the early phase of "the $13^{\text {th }}$ Five-Year Plan" and the motivation of the environment with low competition pressure. Considering the 


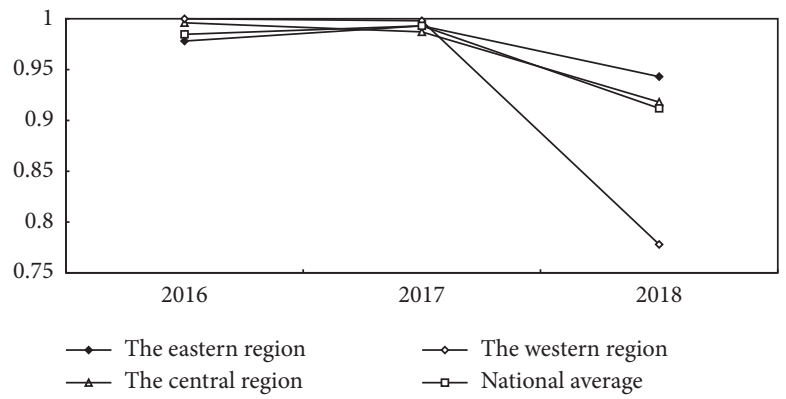

FIGURE 6: Comprehensive efficiency of green innovation in China's listed energy companies from 2016 to 2018.

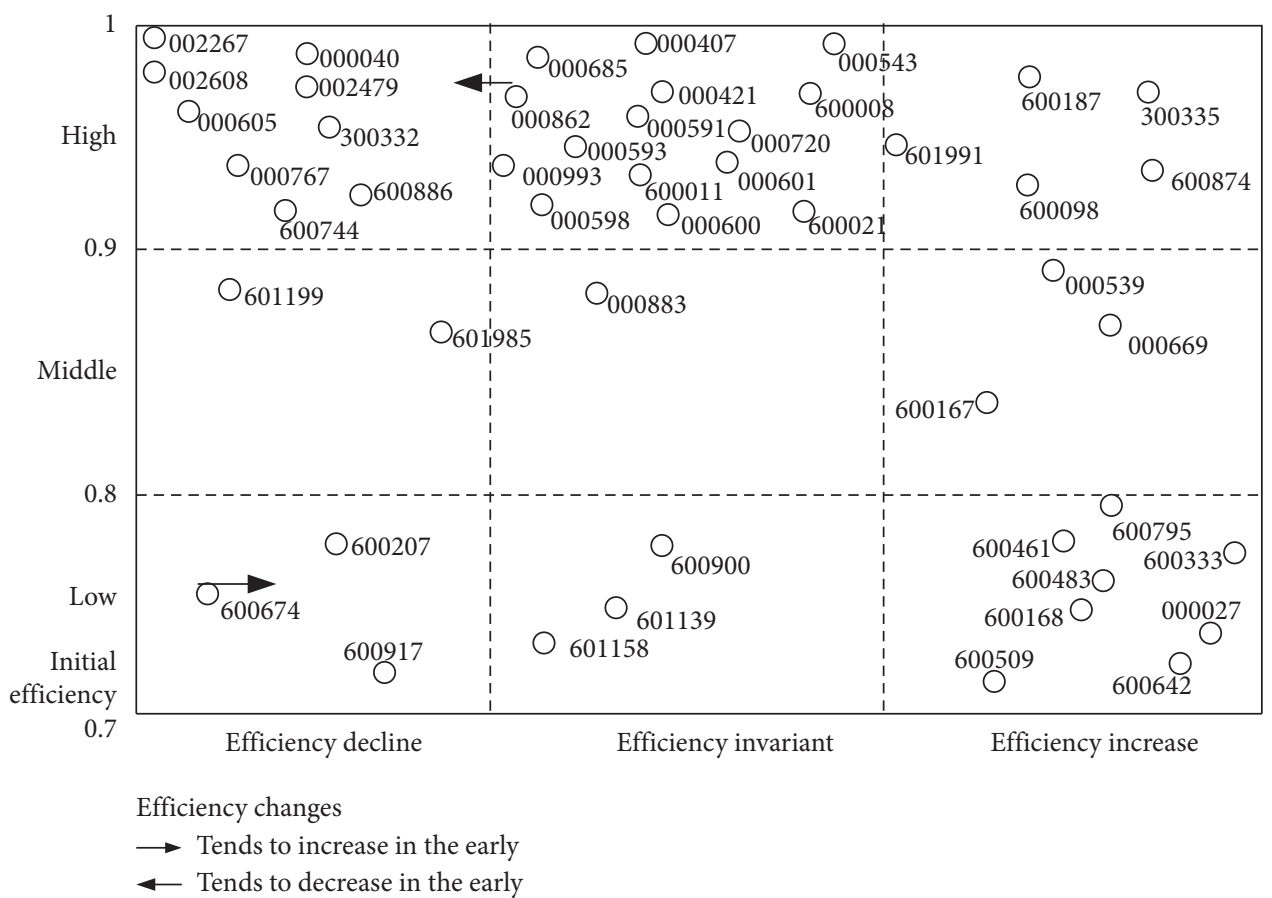

Figure 7: GE matrix of comprehensive efficiency of green innovation of listed energy companies in China.

actual situation, the number of listed energy companies in the eastern and central regions is much higher than that in the western regions, which also has a great impact on the average value of comprehensive efficiency. However, in 2017-2018, the comprehensive efficiency values of Chongqing Water and Chongqing Gas were only 0.288 and 0.281 , resulting in a large fluctuation of the comprehensive efficiency value in the western region. Among the three regions, only the western region had a comprehensive efficiency value of 1 in 2016, which reached the effectiveness requirement of DEA. Although some enterprises in other regions achieved their optimal efficiency, their overall levels were slightly inferior to the western region.

To reflect the space-time evolution path of energy green innovation comprehensive efficiency of listed companies in China, this paper constructs a GE matrix with the horizontal axis representing green innovation comprehensive efficiency changes and the vertical axis representing the initial value of green innovation comprehensive efficiency. The GE matrix divides the green innovation comprehensive efficiency of listed energy companies in China into nine types, as showed in Figure 7. The listed companies are mainly distributed in the four areas of the GE matrix. Among them, listed energy companies such as "Shanxi Gas," "Tunghsu Azure," "Jiangsu Guoxin," "Fuchun Environmental Protection," "Bohai Stock," "Tianhao Environment," "Zhangze Power," "Huajing Power Holdings," and "Huayin Power" are distributed in the range of "high initial efficiency value and decreasing efficiency." "Zhongshan Utilities," "Victory Stock," "Wanneng Power," "Yinxing Power," "Nanjing Utilities," "Solar Energy," "Shouchuang Stock," "Xintai Energy," "Datong Gas," "Mindong Power," "Huaneng International," "Shaoneng Stock," "Xingrong Environment," "Jiantou Energy," and "Shanghai Power" are distributed in the range of "high initial efficiency values and unchanged efficiency," among which the efficiency of "Yinxing Power" decreased at the early stage and then increased. Listed energy 
companies such as "Guozhong Water Supplies," "Disen Stock," "Datang Power," "Guangzhou Development," and "Capital Environment Protection" are distributed in the range of "high initial efficiency value and increasing efficiency." Listed energy companies such as "State Power," "Hongcheng Water Supplies," "Funeng Stock," "Chuangchun Gas," "Wuhan Stock," "Tianfu Energy," and "Shenneng Stock" are distributed in the range of "low initial efficiency value and increasing efficiency." Five other ranges of the GE matrix are dotted with publicly traded energy companies. "Jiangnan Water Supplies" and "China Nuclear Power" are located in the range of "medium initial efficiency value and decreasing efficiency." "Hubei Energy" is located in the range of "medium initial efficiency value and unchanged efficiency." Three energy companies, namely, "Guangdong Electric Power Development," "Lianmei Stock," and "Jinhong Stock," are located in "medium initial efficiency and decreasing efficiency." Three other energy companies "Chuantou Energy," "Ancai Hi-tech," and "Chongqing Gas" are located in the range of "Low initial value and decreasing efficiency," among which "Chuantou Energy" increases in the early stage and then decreases. In the range of "low initial efficiency and unchanged efficiency," there are three companies, namely, "Yangtze Power," "Shenzhen Gas," and "Chongqing Gas." It can be seen that there are different development environments for listed energy companies in China, leading to different changing characteristics of the comprehensive efficiency of green innovation. Therefore, national and local governments should adopt different supporting policies for different enterprises to make full use of government resources.

\section{Conclusions}

Based on green innovation input-output data of 49 listed energy companies in China from 2016 to 2018, this paper studied the green innovation efficiency of listed energy companies in China and its influencing factors by constructing a three-stage window DEA model. The main conclusions are as follows.

Firstly, without eliminating environmental factors and random factors, green innovation economic output efficiency, green innovation social output efficiency, green innovation environmental output efficiency, and green innovation comprehensive efficiency of listed energy companies in China show a V-shaped trend.

Secondly, environmental factors and random factors have influenced the green innovation efficiency of listed Chinese energy companies. To be specific, the level of regional economic development reduces the redundancy of manpower input in green innovation of listed energy companies but increases the redundancy of financial input and material input in green innovation of listed energy companies. Openness is helpful to reduce the redundancy of manpower and financial resources in green innovation of listed energy companies, but it has little impact on the redundancy of material resources in green innovation of listed energy companies. The government's support will increase the redundant human, financial, and material input of listed energy companies in green innovation.

Finally, after removing the interference of environmental factors and random factors, green innovation economic output efficiency of the listed energy companies in China presents as "eastern > central > western" pattern which is consistent with the traditional economic pattern. Social output efficiency of green innovation in the western region is higher than that in the central region, which is in turn higher than that in the eastern region. Environmental output efficiency of green innovation in the central region is relatively stable, while that in the eastern and western regions fluctuates obviously. At the national level, the listed energy companies in China have high comprehensive efficiency of green innovation, but there is a downward trend during the research period. According to the distribution of GE matrix, 49 listed energy companies are mainly distributed in four areas, and just a few listed energy companies are scattered in the remaining five areas of GE matrix.

\section{Data Availability}

The data used to support the findings of this study are available from the corresponding author upon request.

\section{Conflicts of Interest}

The authors declare no conflicts of interest. The funders had no role in the design of the study; in the collection, analyses, or interpretation of data; in the writing of the manuscript; or in the decision to publish the results.

\section{Authors' Contributions}

Zhimin Song conceptualized, investigated, visualized, and administered the project, prepared the methodology, arranged the software, involved in data curation, and wrote the original draft; $\mathrm{Na}$ Zhang and Zhimin Song validated the study and reviewed and edited the draft; and $\mathrm{Na}$ Zhang supervised the research and was responsible for funding acquisition.

\section{Acknowledgments}

This study was supported by the Natural Science Foundation of China (Grant No. 41801119), Social Science Foundation of China (Grant No. 18FGL003), Key Project of National Language Commission (ZDI135-67), China Postdoctoral Science Foundation-funded project (Grant No. 2018M631220), Excellent Youth Foundation of Xinjiang Scientific Committee (Grant No. 2017Q071), and Foundation of Shihezi University (RCSX201754).

\section{References}

[1] National Energy Administration Website, 2020 http://www. nea.gov.cn/zfxxgk/gzbg.html.

[2] China Energy Development Report 2018, 2019, http://www. sznew-victor.com/hangye/3070.html.

[3] M. Granieri and A. Renda, Innovation Law and Policy in the European Union: Towards Horizon 2020, Springer, Berlin, Germany, 2012.

[4] A. Henriques and J. Richardson, The Triple Bottom Line: Does it All Add Up, Routledge, London, UK, 2013. 
[5] J. Elkington, "Enter the triple bottom line," in The Triple Bottom Line, pp. 23-38, Routledge, London, UK, 2013.

[6] H. Bossel, Indicators for Sustainable Development: Theory, Method, Applications, International Institute for Sustainable Development, Winnipeg, Canada, 1999.

[7] J. Schot and F. W. Geels, "Strategic niche management and sustainable innovation journeys: theory, findings, research agenda, and policy," Technology Analysis \& Strategic Management, vol. 20, no. 5, pp. 537-554, 2008.

[8] F. Boons and F. Lüdeke-Freund, "Business models for sustainable innovation: state-of-the-art and steps towards a research agenda," Journal of Cleaner Production, vol. 45, pp. 9-19, 2013.

[9] S. Kusi-Sarpong, H. Gupta, and J. Sarkis, "A supply chain sustainability innovation framework and evaluation methodology," International Journal of Production Research, vol. 57, no. 7, pp. 1990-2008, 2019.

[10] B. S. Silvestre and D. M. Țîrcă, "Innovations for sustainable development: moving toward a sustainable future," Journal of Cleaner Production, vol. 208, pp. 325-332, 2019.

[11] T. Hellström, "Dimensions of environmentally sustainable innovation: the structure of eco-innovation concepts," Sustainable Development, vol. 15, no. 3, pp. 148-159, 2007.

[12] P. Olsson and V. Galaz, "Social-ecological innovation and transformation," in Social Innovation, pp. 223-247, Palgrave Macmillan, London, UK, 2012.

[13] A. Nicholls and A. Murdock, Social Innovation: Blurring Boundaries to Reconfigure Markets, Springer, Berlin, Germany, 2011.

[14] K. Rennings, "Redefining innovation-eco-innovation research and the contribution from ecological economics," Ecological Economics, vol. 32, no. 2, pp. 319-332, 2000.

[15] J. Utzinger, E. K. N'Goran, C. R. Caffrey, and J. Keiser, "From innovation to application: social-ecological context, diagnostics, drugs and integrated control of schistosomiasis," Acta Tropica, vol. 120, pp. S121-S137, 2011.

[16] Y.-S. Chen, "The driver of green innovation and green image green core competence," Journal of Business Ethics, vol. 81, no. 3, pp. 531-543, 2008.

[17] Y.-S. Chen, S.-B. Lai, and C.-T. Wen, "The influence of green innovation performance on corporate advantage in Taiwan," Journal of Business Ethics, vol. 67, no. 4, pp. 331-339, 2006.

[18] T. Schiederig, F. Tietze, and C. Herstatt, "Green innovation in technology and innovation management-an exploratory literature review," R\&D Management, vol. 42, no. 2, pp. 180-192, 2012.

[19] C. C. J. Cheng, "Sustainability orientation, green supplier involvement, and green innovation performance: evidence from diversifying green entrants," Journal of Business Ethics, vol. 161 , no. 2, pp. 393-414, 2020.

[20] A.-N. El-Kassar and S. K. Singh, "Green innovation and organizational performance: the influence of big data and the moderating role of management commitment and $\mathrm{HR}$ practices," Technological Forecasting and Social Change, vol. 144, pp. 483-498, 2019.

[21] D. Zhang, Z. Rong, and Q. Ji, "Green innovation and firm performance: evidence from listed companies in China," Resources, Conservation and Recycling, vol. 144, pp. 48-55, 2019.

[22] Y. Fernando, C. J. Chiappetta Jabbour, and W.-X. Wah, "Pursuing green growth in technology firms through the connections between environmental innovation and sustainable business performance: does service capability matter?" Resources, Conservation and Recycling, vol. 141, pp. 8-20, 2019.

[23] S. B. Brunnermeier and M. A. Cohen, "Determinants of environmental innovation in US manufacturing industries," Journal of Environmental Economics and Management, vol. 45, no. 2, pp. 278-293, 2003.

[24] C. A. Geffen and S. Rothenberg, "Suppliers and environmental innovation," International Journal of Operations \& Production Management, vol. 20, no. 2, 2000.

[25] J. Horbach, "Determinants of environmental innovation-new evidence from German panel data sources," Research Policy, vol. 37, no. 1, pp. 163-173, 2008.

[26] P. H. Driessen and B. Hillebrand, "Adoption and diffusion of green innovations," Marketing for Sustainability: Towards Transactional Policy-Making, pp. 343-355, IOS Press, Amsterdam, Netherlands, 2002.

[27] H. Y. Dai, "Some comments on environmental innovation research," Science Research, vol. 11, pp. 1601-1610, 2009.

[28] S. Liu, "New service development performance," Innovation Management in Knowledge Intensive Business Services in China, vol. 22, no. 5, pp. 17-20, 2012.

[29] Y. Gao, S.-B. Tsai, X. Xue et al., "An empirical study on green innovation efficiency in the green institutional environment," Sustainability, vol. 10, no. 3, p. 724, 2018.

[30] J. C. Guan and S. Z. Liu, "The study on impact of institutions on innovation efficiency in regional innovation systems," Studies in Science of Science, vol. 2, 2003.

[31] Q. Wang, Y. Hang, L. Sun, and Z. Zhao, "Two-stage innovation efficiency of new energy enterprises in China: a nonradial DEA approach," Technological Forecasting and Social Change, vol. 112, pp. 254-261, 2016.

[32] S. Lin, J. Sun, D. Marinova, and D. Zhao, "Evaluation of the green technology innovation efficiency of China's manufacturing industries: DEA window analysis with ideal window width," Technology Analysis \& Strategic Management, vol. 30, no. 10, pp. 1166-1181, 2018.

[33] J. H. Bai, K. S. Jiang, and J. Li, "Analysis of the impact of environment factors on regional innovation efficiency: empirical test based on the DEA-tobit two-step method," R\&D Management, vol. 2, 2009.

[34] C. Weihan and Z. Lin, "Evaluation on cooperative innovation efficiency in Shanghai," Science \& Technology Progress and Policy, vol. 3, 2010.

[35] M. Namazi and E. Mohammadi, "Natural resource dependence and economic growth: a topsis/dea analysis of innovation efficiency," Resources Policy, vol. 59, pp. 544-552, 2018.

[36] W. Wang, B. Yu, X. Yan, X. Yao, and Y. Liu, "Estimation of innovation's green performance: a range-adjusted measure approach to assess the unified efficiency of China's manufacturing industry," Journal of Cleaner Production, vol. 149, pp. 919-924, 2017.

[37] T. Broekel, N. Rogge, and T. Brenner, "The innovation efficiency of German regions-a shared-input DEA approach," Review of Regional Research, vol. 38, no. 1, pp. 77-109, 2018.

[38] J. Shin, C. Kim, and H. Yang, "The effect of sustainability as innovation objectives on innovation efficiency," Sustainability, vol. 10, no. 6, p. 1966, 2018.

[39] W. E. W. Chunyou, "Spatial-temporal differences of provincial eco-efficiency in China based on super efficiency dea model," Chinese Journal of Management, vol. 3, 2011.

[40] F. Lina, C. Xiaohong, and L. Zhihua, "Urban agglomerations eco-efficiency analysis based on super-efficiency DEA model: case study of chang-zhu-tan " $3+5$ " urban agglomeration," 
China Population, Resources and Environment, vol. 23, no. 4, pp. 169-175, 2013.

[41] Y. Wu, Y. Ke, C. Xu, X. Xiao, and Y. Hu, "Eco-efficiency measurement of coal-fired power plants in China using super efficiency data envelopment analysis," Sustainable Cities and Society, vol. 36, pp. 157-168, 2018.

[42] M. L. Tseng and A. S. F. Chiu, "Grey-entropy analytical network process for green innovation practices," Procedia-Social and Behavioral Sciences, vol. 57, pp. 10-21, 2012.

[43] Z. Feng, B. Zeng, and Q. Ming, "Environmental regulation, two-way foreign direct investment, and green innovation efficiency in China's manufacturing industry," International Journal of Environmental Research and Public Health, vol. 15, no. 10, p. 2292, 2018.

[44] C. Miao, D. Fang, L. Sun, and Q. Luo, "Natural resources utilization efficiency under the influence of green technological innovation," Resources, Conservation and Recycling, vol. 126, pp. 153-161, 2017.

[45] J. Jansson, A. Marell, and A. Nordlund, "Green consumer behavior: determinants of curtailment and eco-innovation adoption," Journal of Consumer Marketing, vol. 27, no. 4, pp. 358-370, 2010.

[46] S. K. S. Wong, "Environmental requirements, knowledge sharing and green innovation: empirical evidence from the electronics industry in China," Business Strategy and the Environment, vol. 22, no. 5, pp. 321-338, 2013.

[47] M. Song, J. Tao, and S. Wang, "FDI, technology spillovers and green innovation in China: analysis based on data envelopment analysis," Annals of Operations Research, vol. 228, no. 1, pp. 47-64, 2015.

[48] D. Popp, "Induced innovation and energy prices," American Economic Review, vol. 92, no. 1, pp. 160-180, 2002.

[49] H.-H. Weng, J.-S. Chen, and P.-C. Chen, "Effects of green innovation on environmental and corporate performance: a stakeholder perspective," Sustainability, vol. 7, no. 5, pp. 4997-5026, 2015.

[50] S. Zailani, K. Govindan, M. Iranmanesh, M. R. Shaharudin, and Y. Sia Chong, "Green innovation adoption in automotive supply chain: the Malaysian case," Journal of Cleaner Production, vol. 108, pp. 1115-1122, 2015.

[51] G. Y. Qi, L. Y. Shen, S. X. Zeng, and O. J. Jorge, "The drivers for contractors' green innovation: an industry perspective," Journal of Cleaner Production, vol. 18, no. 14, pp. 1358-1365, 2010.

[52] R. Handayani, S. Wahyudi, and S. Suharnomo, "The effects of corporate social responsibility on manufacturing industry performance: the mediating role of social collaboration and green innovation," Business: Theory and Practice, vol. 18, pp. 152-159, 2017.

[53] S. Y. Lee, "Drivers for the participation of small and mediumsized suppliers in green supply chain initiatives," Supply Chain Management, vol. 13, no. 3, 2008.

[54] J. Elkington, "Triple bottom-line reporting: looking for balance," Australian Corporate Finance \& Accounting, vol. 69, pp. 18-21, 1999.

[55] P. Goel, "Triple bottom line reporting: an analytical approach for corporate sustainability," Journal of Finance, Accounting \& Management, vol. 1, no. 1, 2010.

[56] J. Sarkis and D. G. Dhavale, "Supplier selection for sustainable operations: a triple-bottom-line approach using a bayesian framework," International Journal of Production Economics, vol. 166, pp. 177-191, 2015.

[57] T. Hacking and P. Guthrie, "A framework for clarifying the meaning of triple bottom-line, integrated, and sustainability assessment," Environmental Impact Assessment Review, vol. 28, no. 2-3, pp. 73-89, 2008.

[58] I. E. Nikolaou, K. I. Evangelinos, and S. Allan, "A reverse logistics social responsibility evaluation framework based on the triple bottom line approach," Journal of Cleaner Production, vol. 56, pp. 173-184, 2013.

[59] D. Hollos, C. Blome, and K. Foerstl, "Does sustainable supplier co-operation affect performance? examining implications for the triple bottom line," International Journal of Production Research, vol. 50, no. 11, pp. 2968-2986, 2012.

[60] K. Govindan, R. Khodaverdi, and A. Jafarian, "A fuzzy multi criteria approach for measuring sustainability performance of a supplier based on triple bottom line approach," Journal of Cleaner Production, vol. 47, pp. 345-354, 2013.

[61] B. A. Colbert and E. C. Kurucz, "Three conceptions of triple bottom line business sustainability and the role for HRM," People and Strategy, vol. 30, no. 1, p. 21, 2007.

[62] B. Foran, M. Lenzen, C. Dey, and M. Bilek, "Integrating sustainable chain management with triple bottom line accounting," Ecological Economics, vol. 52, no. 2, pp. 143-157, 2005.

[63] L.-C. Jennifer Ho and M. E. Taylor, "An empirical analysis of triple bottom-line reporting and its determinants: evidence from the United States and Japan," Journal of International Financial Management \& Accounting, vol. 18, no. 2, pp. 123-150, 2007.

[64] M. Painter-Morland, "Triple bottom-line reporting as social grammar: integrating corporate social responsibility and corporate codes of conduct," Business Ethics: A European Review, vol. 15, no. 4, pp. 352-364, 2006.

[65] M. Kucukvar, G. Egilmez, and O. Tatari, "Sustainability assessment of U.S. final consumption and investments: triplebottom-line input-output analysis," Journal of Cleaner Production, vol. 81, pp. 234-243, 2014.

[66] J. D. Cummins, R. Maaria, and Z. Hongmin, The Effect of Organizational Struture on Efficiency: Evidence from the Spanish Insuance Industry, Whatron Financial Insurance Center, Philadelphia, PA, USA, 2003.

[67] H. O. Fried, C. K. Lovell, S. S. Schmidt, and S. Yaisawarng, "Accounting for environmental effects and statistical noise in data envelopment analysis," Journal of Productivity Analysis, vol. 17, no. 1-2, pp. 157-174, 2002.

[68] A. Charnes, C. T. Clark, W. W. Cooper, and B. Golany, A Developmental Study of Data Envelopment Analysis in Measuring the Efficiency of Maintenance Units in the US Air Forces (No. CCS-RR-460), The University of Texas at Austin, Austin, TX, USA, 1983.

[69] G. E. Battese and T. J. Coelli, "Frontier production functions, technical efficiency and panel data: with application to paddy farmers in India," Journal of Productivity Analysis, vol. 3, no. 1-2, pp. 153-169, 1992.

[70] G. Karagiannis and V. Tzouvelekas, "Parametric measurement of time-varying technical inefficiency: results from competing models," Agricultural Economics Review, vol. 10, pp. 50-79, 2009.

[71] Z. Fang, H. Bai, and Y. Bilan, "Evaluation research of green innovation efficiency in China's heavy polluting industries," Sustainability, vol. 12, no. 1, p. 146, 2020.

[72] Z. M. Liu, X. Z. Zhang, and D. Yang, "Temporal and spatial evolution of health input efficiency of provincial governments in China based on panel three-stage DEA model," Journal of Central University of Finance and Economics, vol. 6, pp. 97104, 2014. 